\title{
RADIOECOLOGICAL SITUATION ON THE TERRITORY OF THE VOLGA REGION DEPARTMENT OF HYDROMETEOROLOGY AND ENVIRONMENTAL MONITORING IN 2016
}

(C) 2018

\author{
Zalybina Yuliya Nikolaevna, postgraduate student of Ecology and Environmental Protection Department \\ Grigoriev Vasily Semenovich, doctor of biological sciences, professor, \\ head of Ecology and Environmental Protection Department \\ Sklyuev Valeriy Vitalyevich, candidate of biological sciences, head of Chemistry and Biology Department \\ Samara State Regional Academy (Nayanova) (Samara, Russian Federation)
}

Abstract. The environment quality is an extremely relevant question, including taking into account radioecological situation. The development of local agriculture should take into account various radiation parameters that determine the current radiation situation. In particular, it is necessary to do regular radioecological monitoring of environmental pollution of the Samara Region and adjacent territories on the main types of radiometric observations. The paper focuses on the reliable and rapid detection of radioactive contamination, assessment of the radiation situation with the help of radio-ecological control of natural environment components. In the paper on the basis of the Volga Region Department of Hydrometeorology and Environmental Monitoring data the authors assess the radiation situation in the settlements of Samara, Saratov, Orenburg, Penza and Ulyanovsk Regions. The paper contains values of aerosols $\beta$-activity concentration in the surface layer of the atmosphere as well as the data of the average annual values in Samara and adjacent regions. According to the data of radioecological monitoring the level of total $\beta$ activity of radioactive fallout from the atmosphere is shown. The maximum values of the total $\beta$-activity concentration of the atmospheric surface layer aerosols were recorded in summer, which is due to the secondary wind dust rise from the contaminated areas. It was shown that the average annual value of the total $\beta$-activity of aerosols according to the results of studies is within the normal limits. The paper also contains conclusions about the degree of danger of the atmosphere surface layer contamination by technogenic radionuclides.

Keywords: ambient dose equivalent dose of $\gamma$-radiation (EDR); radioecological monitoring; total $\beta$-activity; average value of dose rate; radiation environment; radiation monitoring; radionuclides; contamination control; radiation safety.

\section{СТРУКТУРА ОРНИТОКОМПЛЕКСОВ ТЕХНОГЕННО НАРУШЕННЫХ ТЕРРИТОРИЙ ЛЕВОБЕРЕЖНОЙ ЧАСТИ ЮЖНО-МИНУСИНСКОЙ КОТЛОВИНЫ}

(C) 2018

Злотникова Тамара Викторовна, кандидат биологических наук, доцент кафедры биологии Хакасский государственный университет им. Н.Ф. Катанова (2. Абакан, Российская Федераџия)

Аннотация. В данной статье рассматривается видовая и экологическая структура орнитологических комплексов на территориях карьерных выемок. Исследования проведены в левобережной части ЮжноМинусинской котловины. Круглогодично исследовали 6 карьеров, эпизодически - 4. Карьеры различного назначения (добыча песка, глины, щебня, складирование бытового мусора), возраста (от 1 года до 15 лет) и размеров (от 1 до 20 га). Выявлено 39 видов птиц, что составляет более 15\% от авифауны котловины. Наибольшим числом видов (по 4-6) представлены семейства Fringillidae, Corvidae, Sylviidae, Muscicapidae. Установлен характер пребывания видов на территории. Гнездящихся видов отмечено 19, посетителей - 20. Только в летний период встречается 25 видов, только в зимний период - 7 видов, ещё 7 видов отмечены на площадках как летом, так и зимой. Гнездятся преимущественно дендрофильные и петрофильные виды. На всех участках отмечено гнездование Passer montanus (L.) и Oenanthe oenanthe (L.), на большинстве - Riparia riparia (L.). Большинство видов синантропные. Показано, что видовое богатство птиц определяется, в первую очередь, структурой местообитания: наличие вертикальных обрывов грунта, каменных сооружений, деревьев, кустарников, травяного покрова, водоёмов. Определённое значение имеют также наличие пищевых отходов и характер окружающих биотопов.

Ключевые слова: Южно-Минусинская котловина; техногенный ландшафт; карьер; орнитокомплекс; экологические группы птиц; синантропные птицы; петрофильные птицы; дендрофильные птицы; гнездящиеся виды; виды-посетители; места гнездования; структура местообитания; Passer montanus; Oenanthe oenanthe; Riparia riparia.

\section{Введение}

Минусинские межгорные котловины расположены в северной части Алтае-Саянской горной области. Южно-Минусинская - самая южная из них. Меридионально котловину пересекает р. Енисей, разделяя её на правобережную (восточную) и левобережную (западную) части. Левобережная часть административно относится к Республике Хакасия.
Рельеф котловины преимущественно равнинный, средняя высота - 300-400 м над ур. м. Климат резко континентальный. На выровненных водоразделах представлены мелкодерновинные степи, на каменистых субстратах - каменистые степи. Ложбины и северные склоны занимают обеднённые варианты луговых степей, северные склоны сопок высотой 550600 м над ур. м. заняты остепнёнными (преимуще- 
ственно лиственничными) лесами и луговыми степями [1, с. 116-117].

В Республике Хакасия на 1 января 2017 года населённые пункты занимали 68,5 тыс. га, земли промышленности, транспорта и иного назначения 43,8 тыс. га [2, с. 35]. Большая часть нарушенных земель располагается в центральных наиболее освоенных частях Хакасии, в границах левобережной части Южно-Минусинской котловины: 136 населённых пунктов, комплекс горно-добывающих предприятий, дорожная сеть общей протяжённостью около 54,5 тыс. км [3, с. 95]. Суммарная доля таких земель составляет более $2 \%$ от всей площади котловины.

Производство основано преимущественно на добыче полезных ископаемых, ежегодный рост которой в последние годы отмечается более чем на $10 \%$ [2, с. 35]. Основную часть извлекаемых полезных ископаемых представляют уголь и строительные материалы, которые добываются карьерным способом.

Несомненно, наблюдаемая техногенная трансформация ландшафтов, связанная с кардинальной сменой рельефа, почв и растительности, оказывает влияние на биологическое разнообразие территории. Изучение закономерностей изменения природных сообществ под воздействием антропогенных факторов - важная задача для планирования рационального природопользования. Птицы в этом плане являются удобной модельной группой организмов, поскольку, обладая высокой пластичностью, адаптируются к жизни рядом с человеком. Зачастую на «мёртвых» техногенных территориях из наземных позвоночных могут существовать только птицы, в силу своей мобильности.
На антропогенное изменение территории птицы реагируют различным образом: изменением поведения, исчезновением каких-либо видов или сокращением либо, наоборот, увеличением численности, введением на территорию новых видов. Всё это приводит к перестройке орнитокомплексов. Эти процессы обладают региональной спецификой.

Работ, посвящённых изучению данных вопросов на территории Южно-Минусинской котловины, мало [4-11]. Кроме того, большая часть из них посвящена отдельным видам.

\section{Цель и объекты исследования}

Цель нашего исследования - выявление видовой и экологической структуры орнитокомплексов на техногенно изменённых территориях левобережной части Южно-Минусинской котловины. Объект исследований - орнитокомплексы карьерных выемок.

\section{Материалы и методика исследований}

Расположение площадок показано на рисунке 1. Основная часть полевых работ проведена в 2010 2016 гг. Исследовали 10 карьеров различного происхождения (добыча угля, песка, гравия, глины, полигон для твёрдых бытовых отходов). Возраст карьеров от 1 года до 15 лет, площадь выемок от 1 до 20 га.

Для учётов птиц использовали метод круговых площадок [12]. Шесть площадок обследовали круглогодично: во внегнездовое время учёты проводили не реже двух раз в месяц, в период гнездования (апрель-июнь) от 2 до 6 раз в месяц. Четыре площадки изучали эпизодически, преимущественно в летнее время. Наименования и систематическое положение птиц приведены по Л.С. Степаняну [13].

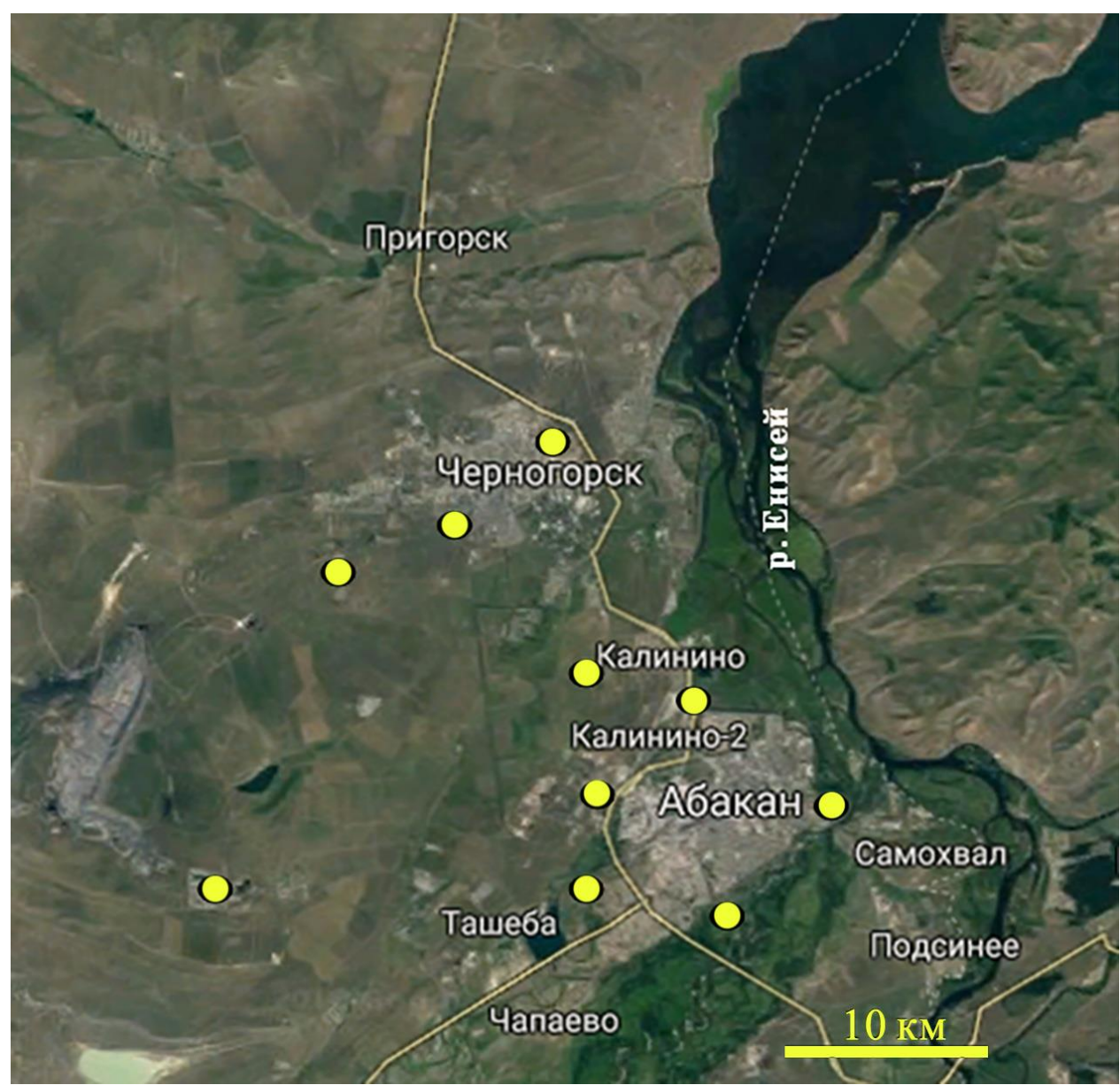

Рисунок 1 - Географическое положение исследуемых карьеров 


\section{Результаты исследований и их обсуждение}

Отмечено 39 видов птиц, регулярно пребывающих на площадках - гнездящихся и (или) кормящихся (табл. 1). Виды, встреченные по 1-2 раза, отнесены в группу «случайные» и в список не включены.

Таблица 1 - Систематический список птиц техногенных территорий

\begin{tabular}{|c|c|c|}
\hline $\begin{array}{c}\text { № } \\
\Pi / \Pi\end{array}$ & $\begin{array}{c}\text { Виды птиц } \\
\text { и их систематическое } \\
\text { положение }\end{array}$ & $\begin{array}{c}\text { Характер } \\
\text { пребывания }\end{array}$ \\
\hline \multicolumn{3}{|c|}{$\begin{array}{l}\text { Отряд Falconiformes } \\
\text { Семейство Accipitridae }\end{array}$} \\
\hline 1 & Milvus migrans (Boddaert, 1783) & $\Gamma ;$ л \\
\hline \multicolumn{3}{|c|}{ Семейство Falconidae } \\
\hline 2 & Falco tinnunculus Linnaeus, 1758 & г; Л \\
\hline \multicolumn{3}{|c|}{$\begin{array}{c}\text { Отряд Galliformes } \\
\text { Семейство Phasianidae }\end{array}$} \\
\hline 3 & Perdix daurica Pallas, 1811 & п; л, 3 \\
\hline \multicolumn{3}{|c|}{$\begin{array}{l}\text { Отряд Charadriiformes } \\
\text { Семейство Charadriidae }\end{array}$} \\
\hline 4 & Charadrius dubius Scopoli, 1786 & г; л \\
\hline \multicolumn{3}{|c|}{ Семейство Laridae } \\
\hline 5 & Larus canus Linnaeus, 1758 & п; л \\
\hline \multicolumn{3}{|c|}{$\begin{array}{l}\text { Отряд Columbiformes } \\
\text { Семейство Columbidae }\end{array}$} \\
\hline 6 & Columba livia Gmelin, 1789 & п; л, 3 \\
\hline \multicolumn{3}{|c|}{$\begin{array}{l}\text { Отряд Cuculiformes } \\
\text { Семейство Cuculidae }\end{array}$} \\
\hline 7 & Cuculus canorus Linnaeus, 1758 & п; л \\
\hline \multicolumn{3}{|c|}{$\begin{array}{l}\text { Отряд Upupiformes } \\
\text { Семейство Upupidae }\end{array}$} \\
\hline 8 & Upupa epops Linnaeus, 1758 & г, л \\
\hline \multicolumn{3}{|c|}{$\begin{array}{l}\text { Отряд Piciformes } \\
\text { Семейство Picidae }\end{array}$} \\
\hline 9 & $\begin{array}{l}\text { Dendrocopos major } \\
\text { (Linnaeus, 1758) }\end{array}$ & п; л, 3 \\
\hline 10 & $\begin{array}{l}\text { Dendrocopos minor } \\
\text { (Linnaeus, 1758) }\end{array}$ & п; л, 3 \\
\hline \multicolumn{3}{|c|}{$\begin{array}{c}\text { Отряд Passeriformes } \\
\text { Семейство Hirundinidae }\end{array}$} \\
\hline 11 & Riparia riparia Linnaeus, 1758 & $\Gamma ; \pi$ \\
\hline \multicolumn{3}{|c|}{ Семейство Motacillidae } \\
\hline 12 & Motacilla flava Linnaeus, 1758 & г; л \\
\hline 13 & Motacilla personata Gould, 1861 & г; л \\
\hline \multicolumn{3}{|c|}{ Семейство Laniidae } \\
\hline 14 & Lanius cristatus Linnaeus, 1758 & п; л \\
\hline \multicolumn{3}{|c|}{ Семейство Sturnidae } \\
\hline 15 & Sturnus vulgaris Linnaeus, 1758 & п; л \\
\hline \multicolumn{3}{|c|}{ Семейство Oriolidae } \\
\hline 16 & Oriolus oriolus Linnaeus, 1758 & п; л \\
\hline \multicolumn{3}{|c|}{ Семейство Corvidae } \\
\hline 17 & Pica pica (Linnaeus, 1758) & $\Gamma, 3$ \\
\hline 18 & Corvus monedula Linnaeus, 1758 & п; л \\
\hline 19 & Corvus frugilegus Linnaeus, 1758 & П; Л \\
\hline 20 & Corvus corone Linnaeus, 1758 & г; л, 3 \\
\hline 21 & Corvus corax Linnaeus, 1758 & п; л, 3 \\
\hline \multicolumn{3}{|c|}{ Семейство Bombycillidae } \\
\hline 22 & $\begin{array}{l}\text { Bombycilla garrulous } \\
\text { (Linnaeus, 1758) }\end{array}$ & $\Pi ; 3$ \\
\hline
\end{tabular}

\begin{tabular}{|c|c|c|}
\hline \multicolumn{3}{|c|}{ Семейство Sylviidae } \\
\hline 23 & $\begin{array}{l}\text { Acrocephalus dumetorum } \\
\text { Dlyth, } 1849\end{array}$ & г; л \\
\hline 24 & $\begin{array}{l}\text { Hippolais caligata } \\
\text { (Lichtenstein, 1823) }\end{array}$ & г; л \\
\hline 25 & Sylvia curruca (Linnaeus, 1758) & $\Gamma ; л$ \\
\hline 26 & $\begin{array}{l}\text { Phylloscopus collybita } \\
\text { (Vieillot, 1817) }\end{array}$ & г; л \\
\hline \multicolumn{3}{|c|}{ Семейство Muscicapidae } \\
\hline 27 & Saxicola torquata (Linnaeus, 1766) & $\Gamma ;$ л \\
\hline 28 & $\begin{array}{l}\text { Oenanthe oenanthe } \\
\text { (Linnaeus, 1758) }\end{array}$ & г; л \\
\hline 29 & $\begin{array}{l}\text { Phoenicurus phoenicurus } \\
\text { (Linnaeus, 1758) }\end{array}$ & г; л \\
\hline 30 & Turdus pilaris (Linnaeus, 1766) & п; л, 3 \\
\hline \multicolumn{3}{|c|}{ Семейство Paridae } \\
\hline 31 & Parus major Linnaeus, 1758 & $\Pi ; 3$ \\
\hline \multicolumn{3}{|c|}{ Семейство Passeridae } \\
\hline 32 & Passer domesticus (Linnaeus, 1758) & п; л \\
\hline 33 & Passer montanus (Linnaeus, 1758) & г; Л, 3 \\
\hline \multicolumn{3}{|c|}{ Семейство Fringillidae } \\
\hline 34 & Fringilla coelebs Linnaeus, 1758 & г; л, \\
\hline 35 & Carduelis canieceps Vigops, 1831 & п; 3 \\
\hline 36 & Carpodacus erythrinus Pallas, 1770 & п; л \\
\hline 37 & Uragus sibiricus Pallas, 1773 & п; 3 \\
\hline 38 & Pyrrhula pyrrhula (Linnaeus, 1758) & $\Pi ; 3$ \\
\hline 39 & $\begin{array}{l}\text { Coccothraustes coccothraustes } \\
\text { (Linnaeus, 1758) }\end{array}$ & п; 3 \\
\hline
\end{tabular}

Примечание. 2 - гнездится; $n$ - посетитель (не гнездится); $л$ - встречается летом; з- встречается зимой.

Для Минусинских межгорных котловин в целом отмечено около 300 видов птиц [14, с. 415-453], в Южно-Минусинской котловине обитает не менее 250 видов. Таким образом, орнитологические комплексы карьеров включают, соответственно, 13 и $15 \%$ видов их авифауны.

Представлены 6 отрядов, доминирует отряд Воробьинообразные, что характерно для авифауны в целом. Наибольшим числом видов представлены семейства Fringillidae (6 видов, 15\%), Corvidae (5 видов, 13\%), Sylviidae и Muscicapidae (по 4 вида и $10 \%)$.

На каждом из карьеров встречено от 10 до 23 видов. На всех площадках гнездились 2 вида Passer montanus и Oenanthe oenanthe. На 8 из 10 карьеров гнездилась Riparia riparia. Виды Passer montanus и Riparia riparia всегда преобладали не только по встречаемости, но и по абсолютной численности. На большинстве площадок встречались Pica pica, Upupa epops, Milvus migrans.

Полагаем, что видовое богатство населения птиц определяется, в первую очередь, структурой местообитания. Наличие вертикальных обрывов грунта, камней, деревьев, кустарников, участков, занятых травяным покровом, временных и постоянных водоёмов, пищевых отходов - всё это привлекает определённые экологические группы или виды птиц.

Проведён анализ с этих позиций состава видов на площадках. Взяты в учёт только постоянно обитающие виды, не рассматривались птицы-посетители.

Виды птиц, встречающиеся только при наличии на площадке обрывов: Riparia riparia. Виды птиц, встречающиеся только при наличии на площадке ка- 
менистых включений (груды камней, строительных материалов): Uрира ерорs, Oenanthe oenanthe, Motacilla personata. Виды птиц, встречающиеся только при наличии на площадке древесно-кустарниковой растительности: Milvus migrans, Falco tinnunculus, Cuculus canorus, Dendrocopos minor, Pica pica, Corvus corone, Sylvia curruca, Phylloscopus collybita, Phoenicurus phoenicurus, Parus major. Виды птиц, встречающиеся только при наличии водоёмов: Charadrius dubius. Виды птиц, встречающиеся только при наличии травяного покрова: Motacilla flava, Acrocephalus dumetorum, Hippolais caligata, Saxicola torquata.

Другой фактор, влияющий на видовое богатство, - возраст и стабильность техногенных местообитаний. Косвенно они связаны и со структурой растительного покрова. Если все элементы ландшафта были «снесены», а затем создавались вновь, то требуется время для того, чтобы они заполнились новыми видами, даже если имеются соответствующие экологические ниши. Это касается не только птиц, но и других животных и растений. Пионерными видами среди птиц в таких «голых» местообитаниях являются Oenanthe oenanthe и Passer montanus. Oenanthe oenanthe насекомоядна, собирает корм на открытых каменистых участках, поэтому техногенные территории для неё наиболее подходящи. Полевой воробей - эврибионтный вид - может собирать корм на земле, на траве, деревьях; может кормиться в любое время года как естественными, так и антропогенными кормами; гнездиться в норах, дуплах, расщелинах деревянных и каменных сооружений, гнёздах сорок.

В карьерах, возраст которых 10 лет и более и которые полностью или частично не используются человеком, задернована почва, достаточно высокие деревья и кустарники, что позволяет обитать здесь разным птицам - до 23 видов.

Нестабильность местообитаний может быть привлекательна для птиц-визитёров. Общеизвестно, что работа людей и техники, перемещения грунтов, выжигание или скашивание растительности, привоз мусора и другие подвижки на территории могут временно облегчать кормодобывание для хищных, всеядных и некоторых насекомоядных птиц. Поэтому с близлежащих территорий прилетают кормиться Milvus migrans, Pica pica, Corvus frugilegus, Corvus corone, Motacilla personata и некоторые другие птицы. Например, сразу после того, как работающая техника или люди покидают территорию, названные виды птиц начинают с воздуха, деревьев, земли осматривать её.

Ещё один фактор, определяющий видовой состав птиц техногенно нарушенных территорий, - характер окружающих естественных биотопов. Более всего, конечно, это сказывается на составе птиц, посещающих техногенные ландшафты в поисках корма. Например, птицы лесного комплекса (Dendrocopos major, Lanius cristatus, Oriolus oriolus, Bombycilla garrulous, Turdus pilaris, Pyrrhula pyrrhula, Coccothraustes coccothraustes) встречаются только в тех техногенных местообитаниях, которые соседствуют с древесными массивами. Чайки - только поблизости от водоёмов.

Установлен характер пребывания видов на территории. Гнездящихся видов отмечено 19, посетителей - 20. Только в летний период встречается 25 видов, только в зимний период -7 , ещё 7 видов отмечены на площадках как летом, так и зимой.
Структура населения птиц по характеру оседлости более, чем видовая, зависит от стабильности местообитаний, а конкретнее - от сезонных изменений условий.

Так, на селитебных территориях основные виды кормов - антропогенные. Растительность слабо влияет на доступность кормов и на укромность. Следовательно, сезонные изменения среды практически не сказываются на условиях обитания птиц. Поэтому здесь доля оседлых видов существенно выше, а перелётных - ниже. В местах карьерных выемок, напротив, снеговой покров, структура травянистой растительности, листва на деревьях и кустарниках подвержены резким сезонным изменениям, соответственно, доля оседлых видов будет ниже.

Структура местообитания, его сложность влияют, в первую очередь, на состав птиц по месту расположения гнезда. На техногенных территориях, изученных нами, вне зависимости от их типа преобладают птицы двух экологических групп по месту расположения гнезда. Это виды, гнездящиеся среди камней и в постройках (петрофилы), а также на деревьях и кустарниках (дендрофилы). Данный факт вполне закономерен - птицы устраивают гнёзда в недоступных местах.

Каких-либо изменений стереотипа расположения гнёзд для изученных нами видов не отметили. Каждый вид устраивает гнездо в соответствии с биологическими особенностями: на земле открыто, на деревьях и кустарниках, среди камней, в норах и т.п.

Укрытиями для гнёзд, располагающихся на земле, могут служить строительный мусор и неровности микрорельефа, связанные с работой техники.

Вместо камней птицы могут находить укрытия среди обломков бетонных плит, железной арматуры, обломков кирпичей.

Норы также могут быть не только вырыты самими птицами (активный норник - Riparia riparia) или иметь естественное происхождение, но и могут являться полостями, оставшимися от перемещений грунта, мусора и т.п.

Количественные учёты показали в целом высокую численность птиц на площадках, сопоставимую с численностью птиц в городских биотопах - до 1000 ос./км². Оперировать средними значениями считаем некорректным, так как для каждой из площадок характерны очень высокие колебания численности птиц и по сезонам, и в отдельные дни внутри сезона (численность меняется в разы). Относительная стабильность наблюдается только в гнездовой период на тех участках, где деятельность людей уже не проявляется.

Высокая численность птиц на техногенно нарушенных территориях объясняется высокой доступностью пищи. Это, в частности, следствие поступления кормов антропогенного происхождения, обилия рудеральных растений, семена которых более доступны. Мозаичность микростаций, в том числе характера субстрата, растительности, освещения, температуры и других абиотических и биотических факторов приводит к агрегированности распределения беспозвоночных - кормов для насекомоядных птиц, обилию грызунов - кормов для хищных птиц и т.п.

Помимо мозаичности микростаций, для территорий карьерных выемок характерны и более резкие, 
чем в природных местообитаниях, сезонные колебания доступности кормов. Поэтому техногенный режим определяет большую сезонную вариабельность, что приводит к резким колебаниям плотности, видового богатства и разнообразия.

Milvus migrans и Falco tinnunculus являются обычными птицами техногенно нарушенных территорий по причине высокой численности грызунов. Всеядные птицы - Pica pica, Corvus corone, Parus major, Passer montanus также питаются пищевыми отходами. Врановые могут также собирать крупных насекомых либо охотиться на мелких видов грызунов.

Антропогенно нарушенные территории могут являться транзитными руслами для птиц-мигрантов различных экологических групп. Так, например, в карьерах, где появляется древесная растительность, останавливаются многие дендрофильные воробьиные птицы.

\section{Bыводы}

Техногенные изменения ландшафта, возникшие на месте обширных однородных территорий, могут несколько увеличить видовое богатство птиц. Это происходит за счёт появления новых стаций. Тем не менее техногенез нельзя считать «полезным», так как привлекаются преимущественно синантропные, толерантные к антропогенным воздействиям виды, вытесняющие виды-аборигены. Появление в степи карьеров привносит новые экологические группы - петрофильные, дендрофильные, околоводные. С другой стороны, фрагментация или полное уничтожение степных местообитаний снижает видовое разнообразие птиц-кампофилов. И если виды, сокращающие численность, могут быть асинантропами, то привносятся более синантропизированные виды.

Плотность населения птиц на техногенно нарушенных территориях, как правило, выше, чем в структурно сходных, но ненарушенных или слабо нарушенных местообитаниях.

Техногенный режим является причиной больших колебаний плотности птиц, в отличие от естественных мест их обитания. Характерны резкие скачки численности, особенно в период послегнездовых перемещений и кочёвок. Это происходит за счёт перемещения не отдельных особей, а целых групп птиц.

Прослеживается закономерность: чем больше площадь техногенно нарушенной территории, тем выше видовое и экологическое разнообразие авифауны, обусловленное пестротой условий обитания.

\section{Список литературы:}

1. Макунина Н.И. Степи Минусинской котловины // Turczaninowia. 2006. № 9 (4). С. 112-144.

2. Государственный доклад «О состоянии окружающей среды Республики Хакасия в 2016 году». Абакан, 2017. 176 с.
3. Павлова Е.В., Махрова М.Л., Ямских Г.Ю. Экологический каркас Южно-Минусинской котловины // Вестник Кемеровского государственного университета. 2015. Т. 2, № 1 (61). С. 90-98.

4. Ким Т.А. К экологии птиц железнодорожных лесополос в Хакасии // Вопросы зоологии. Проблемы высш. нервн. деят-ти человека и животных. Красноярск, 1968. С. 35-41.

5. Владышевский Д.В. Птицы в антропогенном ландшафте. Новосибирск, 1975. 199 с.

6. Кустов Ю.И. К экологии чёрного коршуна в антропогенном ландшафте Минусинской котловины // Гнездовая жизнь птиц: респуб. сб. науч. тр. Пермь, 1979. С. $80-82$.

7. Кустов Ю.И., Фартунов А.П. Особенности гнездования и кормодобывательной деятельности некоторых хищных птиц в антропогенном ландшафте // Новые проблемы зоологической науки и их отражение в вузовском преподавании: тез. докл. науч. конф. зоологов пед. ин-тов. Ставрополь, 1979. C. 281-282.

8. Прокофьев С.М. Состав и структура населения птиц полезащитных лесных полос Минусинской котловины // Изучение птиц СССР, их охрана и рациональное использование: тез. докл. 1 съезда Всесоюзн. орнитол. об-ва. Л., 1986. С. 172-173.

9. Прокофьев С.М. Птицы полезащитных лесонасаждений Минусинской котловины // Роль заповедников в социально-экономическом развитии регионов: науч. тр. запов. «Хакасский». Абакан, 2001. C. $125-151$.

10. Злотникова Т.В., Вдовина О.С., Горлова Т.А., Михеева Ю.А. Особенности гнездовой биологии некоторых видов птиц в антропогенных ландшафтах Минусинской котловины // Животное население и растительность бореальных лесов и лесостепей Средней Сибири: межвуз. сб. науч. трудов. Вып. 1. Красноярск: РИО КГПУ, 2000. С. 78-85.

11. Злотникова Т.В., Кулакова М.В. Некоторые аспекты кормления птиц в местах концентрации пищевых отходов // Вестник Хакасского государственного университета им. Н.Ф. Катанова. 2012. № 1. C. 23-26.

12. Симонов С.Б. К методике учёта птиц на круговых площадках // Зоологический журнал. 1985. T. LIX, № 1. C. 124-129.

13. Степанян Л.С. Конспект орнитологической фауны России и сопредельных территории (в границах СССР как исторической области). М.: Академкнига, 2003. 808 с.

14. Баранов А.А. Птицы Алтай-Саянского экорегиона: пространственно-временная динамика биоразнообразия: монография. Т. I. Красноярск, 2012. $464 \mathrm{c}$.

\section{ORNITHOLOGICAL COMPLEXES' STRUCTURE OF TECHNOGENICALLY DISTURBED TERRITORIES OF THE LEFT-BANK PART OF THE SOUTH MINUSINSK BASIN} (C) 2018

Zlotnikova Tamara Viktorovna, candidate of biological sciences, associate professor of Biology Department Katanov Khakass State University (Abakan, Russian Federation)

Abstract. This paper deals with the species' and ecological structure of ornithological complexes on the territories of quarry excavations. The research was carried out in the left-bank part of the South Minusinsk basin. 6 quarries 
were researched all the year round, 4 quarries were researched incidentally. The quarries were of various purposes (extraction of sand, clay, rubble, storage of domestic garbage), age (from 1 to 15 years) and size (from 1 to 20 hectares). 39 species of birds have been identified, which is more than $15 \%$ of the avifauna of the basin. The largest numbers of species (from 4 to 6 each) are the Fringillidae, Corvidae, Sylviidae, Muscicapidae families. The nature of the species' stay on the territory has been established. Nesting species have been recorded to be 19, visitors -20 . Only in summer there are 25 species, only in winter there are 7 species, 7 species more are marked on sites both in summer and winter. Dendrophilic and petrophilic species are mainly nested. The nesting of Passer montanus (L.) and Oenanthe oenanthe (L.) was marked on all sites, the nesting of Riparia riparia (L.) was marked on the majority sites. Most species are synanthropic. The species' richness of birds is shown to be determined, first of all, by the habitat structure: the presence of vertical soil breaks, stone structures, trees, shrubs, grass cover, reservoirs. The presence of food waste and the nature of the surrounding biotopes are also of particular importance.

Keywords: South Minusinsk basin; technogenic landscape; quarry; ornithocomplex; ecological groups of birds; synanthropic birds; petrophilic birds; dendrophilic birds; nesting species; species-visitors; nesting sites; habitat structure; Passer montanus; Oenanthe oenanthe; Riparia riparia.

УДК 581.9

Статья поступила в редакцию 20.03.2018

\section{ИЗУЧЕНИЕ НЕОДНОРОДНОСТИ ТЕРРИТОРИИ ПО КРИВОЙ «ВИДЫ - ПЛОЩАДЬ» ДЛЯ ИССЛЕДОВАНИЯ ЕЕ ФЛОРИСТИЧЕСКОЙ СТРУКТУРЫ (НА ПРИМЕРЕ СОКСКОГО ФИЗИКО-ГЕОГРАФИЧЕСКОГО РАЙОНА)}

(C) 2018

Иванова Анастасия Викторовна, кандидат биологических наук, научный сотрудник лаборатории проблем фиторазнообразия

Костина Наталья Викторовна, доктор биологических наук, заведующий лабораторией моделирования и управления экосистемами

Институт экологии Волжского бассейна РАН (г. Тольятти, Самарская область, Российская Федерация)

Лысенко Татьяна Михайловна, доктор биологических наук, ведущий научный сотрудник лаборатории проблем фиторазнообразия;

старший научный сотрудник лаборатории общей геоботаники

Институт экологии Волжского бассейна РАН (2. Тольятти, Самарская область, Российская Федерация);

Ботанический институт им. В.Л. Комарова РАН (г. Санкт-Петербург, Российская Федераџия)

Аннотация. Сокский возвышенно-равнинный лесостепной район расположен в северо-западной части Самарской области. Достаточно большая площадь его территории может обеспечивать разнообразие природных условий, в результате возможны различия видового состава флоры его частей.

После накопления данных о распределении видов по территории возможно изучение изменения видового состава в различных направлениях при помощи кривой «число видов - площадь». Зоны наиболее массового притока видов могут рассматриваться как иная флористическая область, имеющая отличающийся видовой состав.

Учитывая географическую конфигурацию Сокского района, изучение производилось по двум направлениям: широтное (с севера на юг и с юга на север), а также по направлению речного русла (от истоков реки Сок к устью и от устья к истокам). При изучении кривой «число видов-площадь» во всех случаях кроме первичного накопления наблюдался рост количества видов в серединной области, а также в конце подъема. Соответственно выявленной неоднородности видового состава флоры Сокского района выделено четыре зоны. Их было предложено считать опорными единицами для изучения флористической структуры территории, то есть определения возможного количества полных флор.

При наращивании списка с увеличением площади кроме увеличения количества видов отслеживалось положение и доля некоторых ведущих семейств. Следует отметить постоянство расположения семейств: при изучении территории во всех случаях они не меняются местами и сохраняют последовательность расположения. Меняется лишь доля семейства в ряду рассматриваемых флористических выборок. Сокский физикогеографический район является типичной территорией для Fabaceae-зоны. На его территории не наблюдается смена типов флор.

Произведена оценка видоспецифичности Сокского физико-географического района относительно граничащего с ним Мелекесско-Ставропольского района, расположенного в лесостепной провинции Низменного Заволжья. Опорные единицы флоры двух районов отличаются в пределах различных флор.

Ключевые слова: семейственный спектр флоры; тип флоры; кривая зависимости «число видов-площадь»; Сокский физико-географический район; опорные флористические единицы.

\section{Введение}

Сокский район является одним из 15 физико-географических районов, которые полностью или частично расположены на территории Самарской и Ульяновской областей [1]. При этом каждый из 15 имеет свои флористические особенности, которые можно выявить путем рассмотрения различных флористических показателей.

Сравнительный анализ семейственных спектров различных физико-географических подразделений рассматриваемой территории выявил определенный полиморфизм их состава. В частности, в ряде случа- 